\title{
Effects of radiation on metastasis and tumor cell migration
}

\author{
Marta Vilalta $^{1} \cdot$ Marjan Rafat $^{1} \cdot$ Edward E. Graves $^{1}$
}

Received: 5 January 2016/Revised: 25 February 2016/Accepted: 22 March 2016

(C) Springer International Publishing 2016

\begin{abstract}
It is well known that tumor cells migrate from the primary lesion to distant sites to form metastases and that these lesions limit patient outcome in a majority of cases. However, the extent to which radiation influences this process and to which migration in turn alters radiation response remains controversial. There are preclinical and clinical reports showing that focal radiotherapy can both increase the development of distant metastasis, as well as that it can induce the regression of established metastases through the abscopal effect. More recently, preclinical studies have suggested that radiation can attract migrating tumor cells and may, thereby, facilitate tumor recurrence. In this review, we summarize these phenomena and their potential mechanisms of action, and evaluate their significance for modern radiation therapy strategies.
\end{abstract}

Keywords Radiotherapy - Cancer - Metastasis ·

Migration $\cdot$ Cytokine $\cdot$ Circulating tumor cells

\section{Introduction}

The primary goal of all cancer treatments is to eradicate any and all tumor cells in the patient, including both the primary tumor as well as any overt or occult metastases, which are a key driver of both prognosis and outcome for patients $[1,2]$. More than $50 \%$ of cancer patients will receive radiation therapy (RT) during the course of their

Edward E. Graves

egraves@stanford.edu

1 Department of Radiation Oncology, Stanford University, 269

Campus Dr., CCSR South Rm. 1255A, Stanford,

CA 94305-5152, USA illness [3], with this therapeutic approach being of prime importance in patients with inoperable tumors or incompletely resected tumors and for those with recurrent disease $[4,5]$. Currently, RT along with surgery and chemotherapy is considered one of the principal treatment modalities in clinical oncology.

While radiation has well-known and well-characterized direct cytotoxic effects on cells and tissues, it has been broadly observed that local treatment of a primary tumor with RT has also other unpredictable systemic effects on tumor growth, such as enhanced growth of distant metastases [6] and inhibition of distant tumor growth, also known as the abscopal effect [7]. Recent studies combining RT and immunotherapies, such as immune checkpoint inhibitors, have also shown systemic antitumor responses [8]. Furthermore, it has also been shown that irradiation of a tumor can have adverse local effects, such as an enhanced tumor cell recruitment of circulating tumor cells (CTCs) from the circulation [9]. However, the relevance of these effects to clinical experience, as well as the mechanisms involved, remains unclear [6]. There remains a need to reconcile these effects demonstrated in preclinical systems with the extensive clinical experience of radiation oncology. It is important to understand both local and systemic effects induced or influenced by RT to minimize recurrences and other adverse effects while optimizing tumor control.

Metastasis occurs through the acquisition of an invasive, migratory phenotype by cancer cells, leading to invasion into local tissues and subsequently entry into the circulation and trafficking to distant sites. Thus, migration of tumor cells is a prerequisite for both invasion and metastasis [10]. Once in the circulation, these CTCs can follow different pathways, such as metastasize to other sites as well as reinfiltrate to their tumor of 
origin, which is called tumor self-seeding and has been demonstrated in breast, colon, and malignant carcinoma $[11,12]$. Here, we review the myriad of effects that radiation has upon the motility mode of tumor cells and the factors that modulate this behavior. These factors include alterations in tumor cells themselves, changes to the microenvironment, and interactions between both of these phenomena.

\section{Effects of radiation on local and distant sites}

\section{Promotion of distant metastasis by radiation}

Enhanced growth of distant metastases after irradiation of a primary tumor has been observed in a variety of experimental animal models. Based on clinical observations of increased local and distant metastasis after subcurative radiation of oral epidermoid carcinoma, Kaplan and Murphy demonstrated this effect in a transplantable mouse model in 1949. They observed an increased rate of lung metastasis in tumor-bearing mice when treated locally with 4-10 Gy of radiation compared with sham-irradiated control mice [13]. Further studies using mammary carcinomas in mice corroborated that low dose $(1 \times 5 \mathrm{~Gy}$ or $2 \times 3.5$ Gy) preoperative irradiation resulted in increased lung metastasis relative to the control group [14]. It was not until 1978 that Strong et al. showed clinically for the first time the unexpected correlation between radiation exposure of a primary tumor and a higher incidence of metastasis in head and neck patients, even though there was no difference in the local recurrence and overall cure rate of the two groups [15]. This effect was also noted in other clinical trials, which showed that subcurative treatments, including radiotherapy of advanced carcinomas of the bladder and the uterine cervix, led to increased metastatic disease [16, 17].

An extensive review by von Essen et al. in 1991 tabulated the number of experimental studies performed to that point concerning metastatic behavior after local tumor irradiation [6]. The consensus of these studies was that the incidence of metastasis following radiotherapy of a primary tumor was enhanced by non-curative radiation doses. Four possible mechanisms for this process were identified. Direct clonogenic alteration of tumor cells was considered unlikely to be responsible, as was alteration of distant sites to increase recruitment of migrating tumor cells through radiotherapy of another site. Instead, it was suggested that the effects of radiation on blood vessels within the tumor may increase the flux of tumor cells into the circulation. Furthermore, the ability of radiation to delay tumor progression may provide additional time for metastasis to occur and to metastases to present clinically. Recent studies leveraging CTCs sorting technology have shown clinically that radiotherapy results in an increased number of viable circulating tumor cells in non-small cell lung cancer [18, 19], and bladder cancer [20], thus contributing to a higher risk of distant metastases.

\section{Inhibition of distant tumors by radiation}

In addition to local bystander effects that can contribute to killing of cells that did not experience direct DNA damage from irradiation [21], experimental and clinical evidence of non-targeted inhibitory effects on distant tumor growth has been found, first reported in 1953 by Mole and termed the abscopal effect [22]. This effect has been observed in several hematological and non-hematological malignancies, including leukemia, lymphoma, melanoma, and other carcinomas. The abscopal effect has been seen to depend on the radiation dose and the p53 status of the tumor being treated [7, 23, 24]. The key components for transmission of abscopal effects include cytokine-mediated inflammatory signaling and the immune system [25-28]. These observations have provided intense interest in the combination of high-dose fractionated RT and immunotherapy, which, in some cases, has been seen to induce long-term tumor regression [27, 28].

\section{Recruitment of circulating tumor cells to irradiated tissues}

A number of clinical and experimental studies have also reported increased metastasis in irradiated normal tissues [6]. These irradiated sites, described by Frankl and Kimball in 1914 [29] and termed the tumor bed in 1995 [30], have been associated with hostile microenvironments, increased hypoxia, and elevated propensity for metastasis. This effect can be observed in experimental models when CTCs are created either endogenously by a solid tumor or artificially through direct injection into the circulation. The proposed mechanisms for this phenomenon point include immunosuppression following RT, radiation-induced damage to local tissue and/or vasculature, production of cytokines in response to radiation, or hypoxia-induced up-regulation of gene products promoting metastatic dissemination $[6,31-$ 33].

Our group has shown recently that this effect can also be detected during focal irradiation of a primary tumor, as shown in Fig. 1. We have shown that irradiation of breast tumor can attract migrating tumor cells circulating in the blood stream through the cytokine granulocyte-macrophage colony stimulating factor (GM-CSF) produced by tumor cells in response to irradiation [9]. Therefore, taken together with previous reports, radiation of a tumor may facilitate both the release of CTCs into the circulation and 


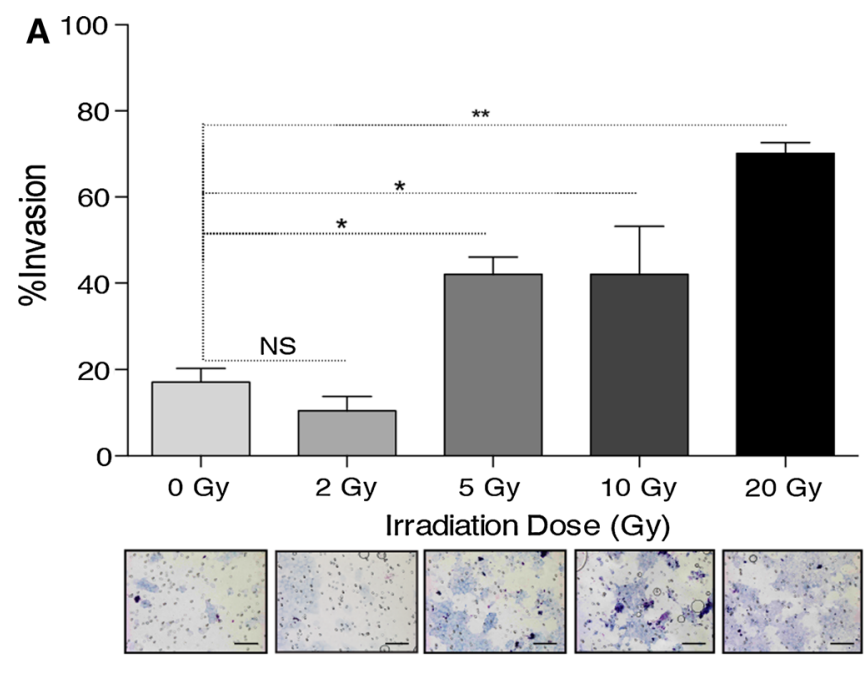

Fig. 1 Radiation attracts migrating tumor cells. Media from murine breast cancer cells irradiated in vitro increases invasion of unirradiated tumor cells in a dose-dependent manner (a), while luciferase-

attraction of these cells to sites of irradiation. Potential mechanisms for these phenomena are discussed in the next section.

\section{Mechanisms of radiation-induced alterations of tumor cell migration}

A recent review by Moncharmont et al. discussing the effects of radiation on cell migration notes that the majority of studies of this topic have been done using primarily in vitro or ex vivo methods [34]. This limits the relevance of the experimental models, their ability to interrogate the process in question, and the generalizability of the findings obtained. Below we examine potential causal mechanisms for alteration of tumor cell migration after radiotherapy, focusing on clinical experiences as well as in vivo preclinical systems to most faithfully capture the complexity of this process and its set of influences.

\section{Hypoxia}

Low oxygen levels (hypoxia) within the tumor microenvironment have been conclusively demonstrated to drive the selection of malignant phenotypes [35-37]. These malignant phenotypes include uncontrolled growth, increased propensity for metastasis, stimulation of angiogenesis, and resistance to radiotherapy and chemotherapy. Radiation-induced reoxygenation has been observed to cause significant up-regulation of tumoral hypoxia inducible factor-1 (HIF-1) activity, which acts as a major regulator of radioprotective cytokines and, therefore,

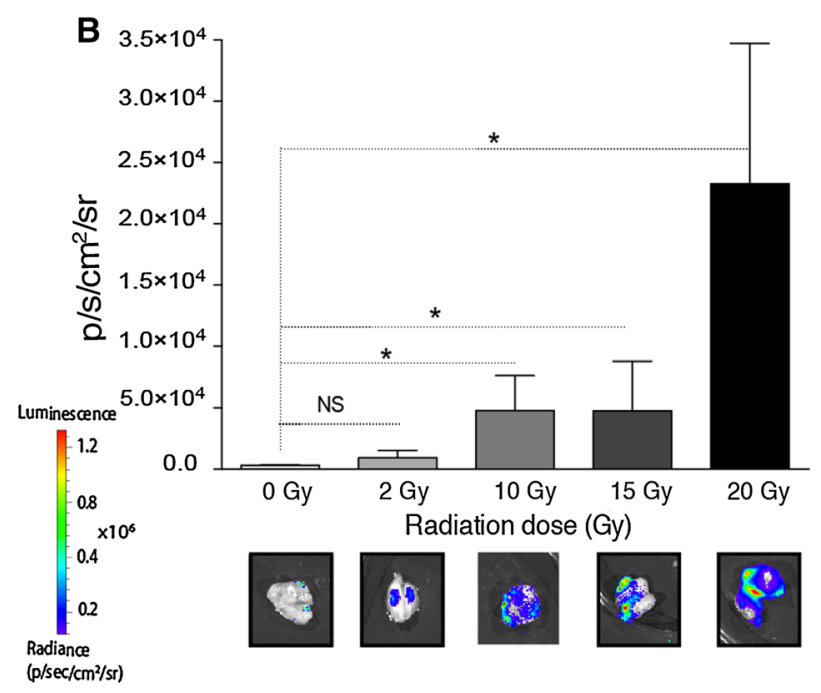

expressing migrating tumor cells are recruited to an irradiated, nonexpressing tumor in vivo with a response that similarly depends on dose (b). Adapted from [9]

regulates the radiosensitivity of the tumor vasculature following RT. This dose-dependent up-regulation occurs between $24 \mathrm{~h}$ and 1 week after radiation exposure, possibly caused by free radical species produced upon irradiation as well as the depolymerization of stress granules [38-40]. As a consequence, several important downstream targets of HIF-1 are upregulated in irradiated tumors, which may contribute to increased metastasis [31, 41, 42]. The increased fraction of hypoxic cells observed upon recurrence after RT suggests that the targeted inhibition of HIF1 after radiotherapy may improve tumor control; however, the potential impact of this inhibition remains controversial due to the complexity of the HIF-1 signaling pathway [31, 39, 43].

\section{Epithelial-mesenchymal transition}

Epithelial-mesenchymal transition (EMT), a pivotal step in the acquisition of a migratory phenotype by tumor cells, is the process of epithelial cells losing polarity and acquiring mesenchymal properties, such as the maintenance of stemness and induction of migration [44, 45]. This process is initiated by the loss of E-cadherin expression, resulting in the loss of stable intercellular junctions. Hypoxia is a well-established mediator of EMT; however, radiation has also been demonstrated to directly facilitate this transition [46-48], with Bmi-1 playing a key role after activation of PI3K/AKT signaling [49]. Therefore, while not necessarily specific to radiation, therapeutic inhibition of EMT may be useful in enhancing the effects of RT by targeting these collateral effects on migration and metastasis [3, 50]. 


\section{Vascular damage}

It is well known that RT induces vascular damage in tumors, which can contribute to tumor cell death in addition to the direct action of radiation in producing DNA damage [51]. Park and colleagues reviewed the existing data on the vascular effects of radiotherapy acquired over the last 60 years from both experimental and clinical subjects. They concluded that single fraction doses higher than $10 \mathrm{~Gy}$ induce more severe vascular damage as compared with the conventional hyperfractionated radiotherapy (1.5-2 Gy/day), which can actually improve slightly the function of the vasculature during the early steps of the treatment [52]. However, clinical fractionated RT has been seen to increase the levels of CTCs in the blood, presumably due to disruptions in tumor-associated blood vessels that allow increased influx of migrating tumor cells [18].

It should be noted that many preclinical in vivo studies utilize single fraction treatments with large radiation doses, which may have a distinct radiobiology from the fractionated courses commonly employed clinically. Considerable work remains to be done to establish the correspondence between preclinical and clinical radiotherapy regimens and the responses observed for each. Specifically, the effects of dose per fraction, total dose, tumor volume, tumor location, dose conformality, and dose heterogeneity can vary substantially between preclinical and clinical studies, and the effects of each of these variables on the subsequent radiobiology remain to be elucidated. Recent advances in preclinical radiotherapy technology will facilitate more careful study of these factors [53].

\section{Cytokine expression}

Radiation promotes the release of cytokines and growth factors through the induction of a damage response [54]. Secreted by tumor, immune, or normal cells, many of these cytokines are involved in promoting tumor cell migration, invasion, and metastasis following radiotherapy. Furthermore, some of these cytokines may also be involved in attracting CTCs $[9,12]$.

\section{Secretion by tumor cells}

It has been shown that radiation induces the secretion of a number of cytokines that alter cell migration and invasion for several tumor types. In malignant gliomas, RT induces the secretion of interleukins 6 and 8 (IL-6, IL-8) and growth factors, such as transforming growth factor $\beta$ (TGF$\beta$ ) and vascular endothelial growth factor (VEGF) that contribute to increased cell motility, thus affecting tumor invasion and migration [55-58]. The secretion of matrix metalloproteinases (MMPs) following irradiation has also been shown to enhance invasion and migration of brain tumors [59, 60]. For example, in vitro irradiation of malignant glioma cells increases invasiveness, migration, proliferation, and angiogenesis through the secretion of MMP2 [60, 61]. Stromal cell-derived factor-1 (SDF-1) secreted by breast and lung tumors in response to radiation has been shown to enhance tumor invasiveness through the recruitment of bone marrow derived cells (BMDCs) when interacting with $\mathrm{C}-\mathrm{X}-\mathrm{C}$ chemokine receptor type 4 (CXCR4) [62, 63]. Other factors, including connective tissue growth factor (CTGF) mRNA and insulin-like growth factor binding protein 2 (IGFBP2) secreted by neoplastic cells, have been shown to enhance cell migration in recipient cells [64].

Radiation-induced secretion of cytokines and growth factors has also been shown to be significant in several other tumor types. Irradiation of human MDA-MB-231 and MCF7 mammary carcinoma cells promotes the secretion of IL- $1 \beta$ and IL-6 and platelet-derived growth factor (PDGF-BB), respectively, which enhance invasiveness [65, 66]. In murine 4T1 mammary carcinoma cells and human MDA-MB231 cells, RT stimulates tumor cell production of GM-CSF, which significantly enhanced the migration and recruitment of CTCs in vivo [9]. The invasiveness and the migration of pancreatic carcinoma cells and neuroblastoma cells are also affected upon irradiation through up-regulation of c-Met/ hepatocyte growth factor (HGF) signaling [67, 68]. Overall, radiotherapy enhances cytokine and soluble factor secretion in tumor cells that directly influence tumor cell migration and invasion, which could negatively impact tumor control in vivo. Unpublished results from our group suggest that this effect is not due to random chemokinesis but to directed chemotaxis. However, further experiments to clarify this phenomenon are needed.

\section{Secretion by stromal cells}

Radiation-induced cytokine secretion is also altered in other components of the tumor microenvironment, such as the surrounding normal and stromal cells, including cancerassociated fibroblasts (CAFs) [69]. CAFs differ from normal fibroblasts in that they acquire a modified phenotype through interaction with tumor cells [70]. Many studies have investigated the effect of irradiation on stromal cell cytokine profiles that influence tumor cell migration. In vitro irradiation of normal fibroblasts has been shown to promote invasion of pancreatic cancer cells through the secretion of soluble factors, including basic fibroblast growth factor (bFGF) and activation of the c-Met/HGF system [71]. Hepatoma cells are similarly affected through the radiation-induced fibroblast secretion of tumor necrosis factor alpha (TNF- $\alpha$, IL-6, VEGF, epidermal growth factor (EGF), MMP2, and MMP9 [72]. In vivo preirradiation of 
mouse mammary glands increases promigratory cyclooxygenase-2 (COX2) and IL-6 expression in the microenvironment, which increases the number of circulating tumor cells and the number of lung metastases [73]. TGF- $\beta$ secreted from stromal cells following irradiation has been shown to promote tumor migration and invasiveness in vitro in squamous cell carcinoma [74], and to increase CTCs and lung metastases in orthotopic mammary tumors [50]. Desmarais and colleagues showed that irradiation of the brain prior to orthotopic implantation of tumor cells resulted in the production of inflammatory cytokines including IL-1 $\beta$ that promoted tumor invasion [75], as shown in Fig. 2. Taken together, radiation-induced cytokine release represents an important form of tumorstromal interaction that can modulate tumor behavior.

\section{Secretion by immune cells}

Radiation has also been shown to influence immune cell recruitment and impact their behaviors. Tumor-associated macrophages (TAMs) and myeloid derived suppressor cells can rapidly infiltrate irradiated sites and promote the secretion of cytokines and growth factors that can alter tumor growth and cell mobility [62, 76, 77]. Increased production of TNF- $\alpha$, IL-1, TGF- $\beta 1$, and growth factors, including PDGF and IGF-1 [78-82], has been observed in macrophages exposed to RT [83]. Understanding the differential regulation of these factors in influencing tumor invasion and metastasis provides valuable targets for mitigating potentially deleterious therapy-induced effects.

\section{Reconciling preclinical and clinical experience}

Despite the multitude of experimental data documenting the effects of radiotherapy on migrating tumor cells and established metastasis, there has been skepticism within radiation oncology of the significance of these findings.

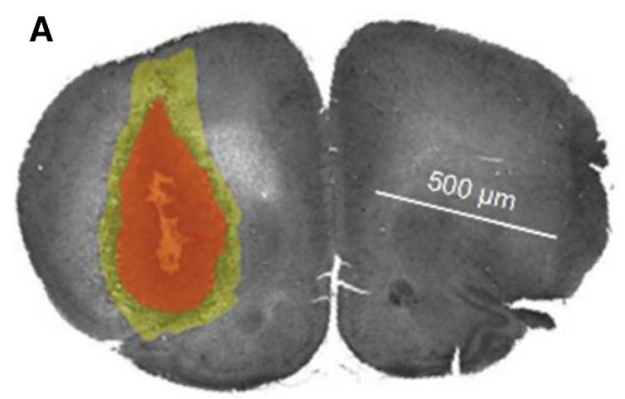

Fig. 2 Whole brain irradiation delivered prior to orthotopic implantation of a glioma in a rat model resulted in a decrease in tumor growth (red volume) but an increase in tumor cell infiltration (yellow
This is largely due to the lack of clinical data showing these processes are occurring in human cancer patients treated with typical conventional radiotherapy regimens. The initial demonstrations of the effects of radiation on tumor cell migration and metastasis [13], and indeed many more recent investigations $[9,31]$, have studied subcurative radiation doses. These radiation courses were seen to result in increased metastasis, whereas both preclinical and clinical studies focusing on curative radiotherapy showed no significant effect on the metastatic frequency. With recent improvements in the ability of radiotherapy to conformally target tumors and spare normal tissue, escalation of radiation doses has occurred for many types of tumors, resulting in improvements in local tumor control that would not be associated with increased metastasis based on these early findings [84]. The relationship between subcurative radiotherapy and enhanced metastasis suggests an increase in the supply of viable CTCs into the systemic circulation. As radiation dose to the tumor increases, the flow of cells into the bloodstream may continue to increase; however, the percentage of viable cells will be reduced from the effects of the treatment. Emergence of previously occult distant metastases long after primary treatment may be expected due to the improved local control and extended survival obtained through modern radiation treatments, but this is likely independent of the effects of the treatment.

In addition to reluctance within radiation oncology to believe that radiotherapy could increase metastasis and contribute to tumor progression, there has similarly been controversy over whether an abscopal effect of radiation could enhance tumor control. While this phenomenon was first observed in 1953 [22], it has proved that rare and clinical evidence of it in the literature consists largely of individual case reports [27, 85]. A variety of preclinical models of this phenomenon have been developed and applied to probe the mechanism of this response; however, this disparity between preclinical investigation and clinical

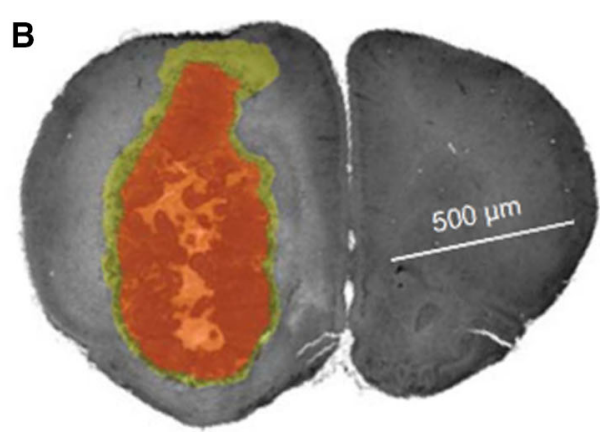

volume) (a) relative to controls in which no radiation was given (b). This effect was found to correlate with radiation-induced increases in interleukin-1 $\beta$ (IL-1 $\beta$ ). Adapted from [75] 
experience has contributed to the ongoing debate over the translational utility of mouse models of cancer. Given basic research identifying immune mechanisms for the abscopal effect, including production of immune-stimulating cytokines, such as interferon- $\gamma$ and activation of dendritic cells, $\mathrm{T}$ cells, and natural killer cells, and interest in reproducibly generating abscopal effects after radiotherapy, has intensified following recent successes with immunotherapies. While a small fraction of patients has exhibited sustained tumor regression after combined radiotherapy and immunotherapy treatments, it remains to be seen whether refinement of these therapeutic approaches can routinely exploit the abscopal effect.

Recently, several publications have noted that metastatic tumor cells can return to their tumors of origin, and that this trafficking may be stimulating by factors both intrinsic and extrinsic to the primary tumor $[9,12]$. The tumor microenvironment is one that gave rise to metastatic tumor cells originally, and, therefore, represents a welcoming site for these migrating cells relative to potentially adverse conditions found in other organs they might colonize. This process may facilitate evolution of a tumor to a more aggressive phenotype through the selection for cells that have successfully intravasated, circulated, and returned. We previously demonstrated that RT may stimulate this process through the production of GM-CSF, and that these migrating cells may facilitate tumor regrowth after focal therapy [9]. The clinical relevance of these biological observations remains unclear, however. Migration of tumor cells back to the primary tumor may be of limited prognostic significance if the patient exhibits widespread metastatic disease that will ultimately dictate outcome. However, many tumor types are known to seed micro- or occult metastases that may remain dormant for years before progressing [86]. Interestingly, GM-CSF has also been shown clinically to promote an abscopal response to distant metastasis sites in combination with local RT through dendritic cell activation [87]. It is worth considering whether radiation could act as a stimulus to mobilize previously dormant micrometastases. As discussed above, there is a lack of evidence to suggest this process results in increased metastasis after radiation, but this phenomenon could manifest as a reduction in local control and corresponding increase in tumor recurrence. Efforts to accurately detect and count CTCs in the blood could be utilized to predict this occurrence on a patient-by-patient basis [19].

Under what circumstances could radiation-induced tumor cell migration alter the therapeutic response of tumors? Historically, tumor response to radiation has been modeled as a sigmoid, as shown in Fig. 3. If recruitment of migrating tumor cells to irradiated tumors increases linearly with dose as demonstrated previously for murine

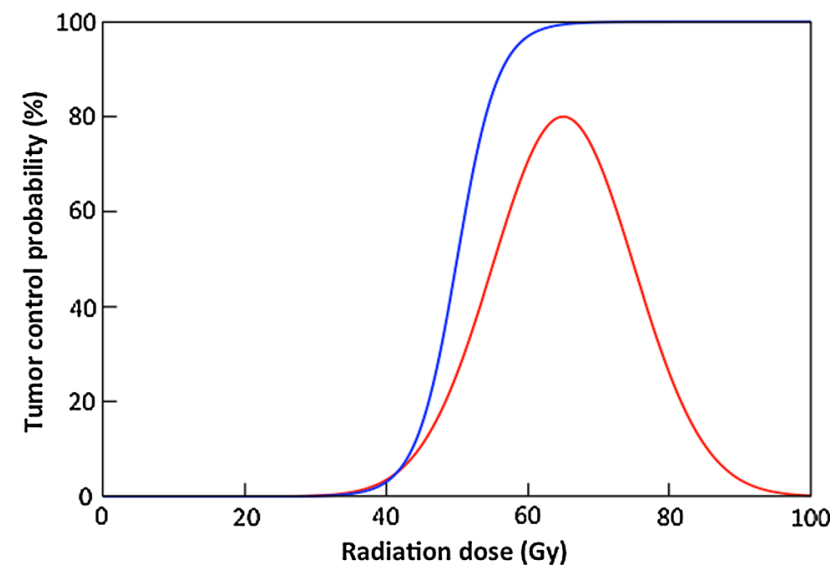

Fig. 3 Tumor response to radiation is commonly depicted as "tumor control probability," a relationship that is modeled as a sigmoidal function of dose (blue). Increases in migrating tumor cell recruitment with radiation dose might be expected to cause this function to decrease at large radiation doses (red); however, this has not been observed in preclinical or clinical studies

breast cancer, one might expect that the tumor control curve would not asymptotically approach $100 \%$ as dose increases but would instead begin to decrease at higher doses. There is no preclinical or clinical data to suggest such a deviation. Furthermore, one would expect that the ablative effect of high radiation doses on the target tissue would preclude successful colonization of the site by any migrating tumor cells stimulated to return. However, this phenomenon may play a role in recurrence of tumors that display a limited local response to radiation, including head and neck cancers, lung cancers, and brain tumors. The latter is notoriously infiltrative and radioresistant; these two properties could be fundamentally linked [59]. In addition, it is important to note that even the most conformal radiation treatments produce a dose gradient from the target volume to the background, and tissues within this gradient may receive a dose that is less than ablative but sufficient to recruit migrating tumor cells. These tissues may include tumor cells within the clinical target volume (CTV) prescribed during radiation treatment planning, or normal tissues capable of secreting tumor cell-attracting cytokines in response to irradiation as discussed above. Recruitment of tumor cells to regions receiving an intermediate dose of radiation could explain breast cancer recurrences in the chest wall.

Fractionation could help limit the effects of this phenomenon by killing tumor cells recruited by one radiation fraction through the administration of additional fractions. This would be analogous to the effects of fractionation on tumor reoxygenation and cell cycle redistribution, which are well known to improve therapeutic response [88]. It has been previously observed that continuous hyperfractionated accelerated radiotherapy (CHART), which was 
developed in 1985, delivered to lung cancers improves prognosis and patient survival through reduction of distant metastasis [89]. As hypofractionated treatment strategies have recently been shown to be convenient and effective radiotherapy regimens and are being increasingly used in the clinic, evaluation of both traditional (reoxygenation, redistribution) and novel (tumor cell migration) radiobiology in the context of these treatments is warranted.

In summary, there is an abundance of evidence that radiation can exert local and distant effects on the movement of tumor cells. It has been more than a half century, since the first reports emerged suggesting that incomplete tumor irradiation can promote metastasis, and through preclinical investigations, a number of mechanisms for this altered migration have been identified, including vascular damage, EMT, and cytokine production. The clinical significance of these findings is still unknown, and in the absence of methods to monitor migration of tumor cells in human cancer patients, we must employ indirect techniques to assess whether radiation-induced tumor cell trafficking plays a role in the therapy response of human tumors. A number of causes can be identified to explain tumor recurrence after radiation, including intrinsic cellular radiosensitivity, hypoxia, accelerated repopulation, and others. At present, there is ample evidence to add altered tumor cell migration to this list and to consider multifactorial explanations of tumor response to treatment.

Acknowledgments This work was funded by the National Institutes of Health (P01 CA67166, R01 CA197136) and the California Breast Cancer Research Program (19IB-0106).

\section{References}

1. Hanahan D, Weinberg RA (2000) The hallmarks of cancer. Cell 100(1):57-70

2. Hanahan D, Weinberg RA (2011) Hallmarks of cancer: the next generation. Cell 144(5):646-674. doi:10.1016/j.cell.2011.02.013

3. Park JK, Jang SJ, Kang SW, Park S, Hwang SG, Kim WJ et al (2012) Establishment of animal model for the analysis of cancer cell metastasis during radiotherapy. Radiat Oncol 7:153. doi:10. 1186/1748-717X-7-153

4. Durante M, Loeffler JS (2010) Charged particles in radiation oncology. Nat Rev Clin Oncol 7(1):37-43. doi:10.1038/ nrclinonc.2009.183

5. Baskar R, Dai J, Wenlong N, Yeo R, Yeoh KW (2014) Biological response of cancer cells to radiation treatment. Front Mol Biosci 1:24. doi:10.3389/fmolb.2014.00024

6. von Essen CF (1991) Radiation enhancement of metastasis: a review. Clin Exp Metastasis 9(2):77-104

7. Camphausen K, Moses MA, Menard C, Sproull M, Beecken WD, Folkman J et al (2003) Radiation abscopal antitumor effect is mediated through p53. Cancer Res 63(8):1990-1993

8. Derer A, Frey B, Fietkau R, Gaipl US (2015) Immune-modulating properties of ionizing radiation: rationale for the treatment of cancer by combination radiotherapy and immune checkpoint inhibitors. Cancer Immunol Immunother CII. doi:10.1007/ s00262-015-1771-8

9. Vilalta M, Rafat M, Giaccia AJ, Graves EE (2014) Recruitment of circulating breast cancer cells is stimulated by radiotherapy. Cell Rep. doi:10.1016/j.celrep.2014.06.011

10. Entschladen F, Drell TL, Lang K, Joseph J, Zaenker KS (2004) Tumour-cell migration, invasion, and metastasis: navigation by neurotransmitters. Lancet Oncol 5(4):254-258. doi:10.1016/ S1470-2045(04)01431-7

11. Norton L, Massague J (2006) Is cancer a disease of self-seeding? Nat Med 12(8):875-878. doi:10.1038/nm0806-875

12. Kim MY, Oskarsson T, Acharyya S, Nguyen DX, Zhang XH, Norton L et al (2009) Tumor self-seeding by circulating cancer cells. Cell 139(7):1315-1326. doi:10.1016/j.cell.2009.11.025

13. Kaplan HS, Murphy ED (1949) The effect of local roentgen irradiation on the biological behavior of a transplantable mouse carcinoma; increased frequency of pulmonary metastasis. J Natl Cancer Inst 9(5-6):407-413

14. Sheldon PW, Fowler JF (1976) The effect of low-dose pre-operative $\mathrm{X}$-irradiation of implanted mouse mammary carcinomas on local recurrence and metastasis. Br J Cancer 34(4):401-407

15. Strong MS, Vaughan CW, Kayne HL, Aral IM, Ucmakli A, Feldman M et al (1978) A randomized trial of preoperative radiotherapy in cancer of the oropharynx and hypopharynx. Am J Surg 136(4):494-500

16. Anderson P, Dische S (1981) Local tumor control and the subsequent incidence of distant metastatic disease. Int J Radiat Oncol Biol Phys 7(12):1645-1648

17. Fagundes H, Perez CA, Grigsby PW, Lockett MA (1992) Distant metastases after irradiation alone in carcinoma of the uterine cervix. Int J Radiat Oncol Biol Phys 24(2):197-204

18. Martin OA, Anderson RL, Russell PA, Ashley Cox R, Ivashkevich A, Swierczak A et al (2014) Mobilization of viable tumor cells into the circulation during radiation therapy. Int J Radiat Oncol Biol Phys 88(2):395-403. doi:10.1016/j.ijrobp.2013.10. 033

19. Dorsey JF, Kao GD, MacArthur KM, Ju M, Steinmetz D, Wileyto EP et al (2015) Tracking viable circulating tumor cells (CTCs) in the peripheral blood of non-small cell lung cancer (NSCLC) patients undergoing definitive radiation therapy: pilot study results. Cancer 121(1):139-149. doi:10.1002/cncr.28975

20. Ju M, Kao GD, Steinmetz D, Chandrasekaran S, Keefe SM, Guzzo TJ et al (2014) Application of a telomerase-based circulating tumor cell (CTC) assay in bladder cancer patients receiving postoperative radiation therapy: a case study. Cancer Biol Ther 15(6):683-687. doi:10.4161/cbt.28412

21. Marin A, Martin M, Linan O, Alvarenga F, Lopez M, Fernandez L et al (2015) Bystander effects and radiotherapy. Rep Pract Oncol Radiother 20(1):12-21. doi:10.1016/j.rpor.2014.08.004

22. Mole RH (1953) Whole body irradiation; radiobiology or medicine? Br J Radiol 26(305):234-241. doi:10.1259/0007-1285-26305-234

23. Strigari L, Mancuso M, Ubertini V, Soriani A, Giardullo P, Benassi $M$ et al (2015) Abscopal effect of radiation therapy: interplay between radiation dose and p53 status. Int J Radiat Biol 91(3):294. doi:10.3109/09553002.2014.997514

24. Komarova EA, Diatchenko L, Rokhlin OW, Hill JE, Wang ZJ, Krivokrysenko VI et al (1998) Stress-induced secretion of growth inhibitors: a novel tumor suppressor function of p53. Oncogene 17(9):1089-1096. doi:10.1038/sj.onc. 1202303

25. Demaria S, Ng B, Devitt ML, Babb JS, Kawashima N, Liebes L et al (2004) Ionizing radiation inhibition of distant untreated tumors (abscopal effect) is immune mediated. Int J Radiat Oncol Biol Phys 58(3):862-870. doi:10.1016/j.ijrobp.2003.09.012 
26. Formenti SC, Demaria S (2009) Systemic effects of local radiotherapy. Lancet Oncol 10(7):718-726. doi:10.1016/S14702045(09)70082-8

27. Postow MA, Callahan MK, Barker CA, Yamada Y, Yuan J, Kitano $S$ et al (2012) Immunologic correlates of the abscopal effect in a patient with melanoma. New England $\mathbf{J}$ Med 366(10):925-931. doi:10.1056/NEJMoa1112824

28. Siva S, MacManus MP, Martin RF, Martin OA (2015) Abscopal effects of radiation therapy: a clinical review for the radiobiologist. Cancer Lett 356(1):82-90. doi:10.1016/j.canlet.2013.09.018

29. Frankl O, Kimball CP (1914) Über die Beeinflussung von Mäusetumoren durch Röntgenstrahlen. Wien Klin Wochenschr 27:1448-1450

30. Stenström KW, Vermund H, Mosser GG, Marvin JF (1955) Effects of Roentgen irradiation on the tumor bed. I. The inhibiting action of local pretransplantation Roentgen irradiation $(1500 \mathrm{r})$ on the growth of mouse mammary carcinoma. Radiat Res 2:180-191

31. Rofstad EK, Mathiesen B, Galappathi K (2004) Increased metastatic dissemination in human melanoma xenografts after subcurative radiation treatment: radiation-induced increase in fraction of hypoxic cells and hypoxia-induced up-regulation of urokinase-type plasminogen activator receptor. Cancer Res 64(1):13-18

32. Rofstad EK, Mathiesen B, Henriksen K, Kindem K, Galappathi K (2005) The tumor bed effect: increased metastatic dissemination from hypoxia-induced up-regulation of metastasis-promoting gene products. Cancer Res 65(6):2387-2396. doi:10.1158/00085472.CAN-04-3039

33. Lee EJ, Park HJ, Lee IJ, Kim WW, Ha SJ, Suh YG et al (2014) Inhibition of IL-17A suppresses enhanced-tumor growth in low dose pre-irradiated tumor beds. PLoS One 9(9):e106423. doi:10. 1371/journal.pone.0106423

34. Moncharmont C, Levy A, Guy JB, Falk AT, Guilbert M, Trone JC et al (2014) Radiation-enhanced cell migration/invasion process: a review. Crit Rev Oncol Hematol 92(2):133-142. doi:10. 1016/j.critrevonc.2014.05.006

35. Young SD, Marshall RS, Hill RP (1988) Hypoxia induces DNA overreplication and enhances metastatic potential of murine tumor cells. Proc Natl Acad Sci USA 85(24):9533-9537

36. Brown JM (1999) The hypoxic cell: a target for selective cancer therapy-eighteenth Bruce F. Cain Memorial Award lecture. Cancer Res 59(23):5863-5870

37. Sullivan R, Graham CH (2007) Hypoxia-driven selection of the metastatic phenotype. Cancer Metastasis Rev 26(2):319-331. doi:10.1007/s10555-007-9062-2

38. Moeller BJ, Cao Y, Li CY, Dewhirst MW (2004) Radiation activates HIF-1 to regulate vascular radiosensitivity in tumors: role of reoxygenation, free radicals, and stress granules. Cancer Cell 5(5):429-441

39. Moeller BJ, Dreher MR, Rabbani ZN, Schroeder T, Cao Y, Li CY et al (2005) Pleiotropic effects of HIF-1 blockade on tumor radiosensitivity. Cancer Cell 8(2):99-110. doi:10.1016/j.ccr. 2005.06.016

40. Moeller BJ, Richardson RA, Dewhirst MW (2007) Hypoxia and radiotherapy: opportunities for improved outcomes in cancer treatment. Cancer Metastasis Rev 26(2):241-248. doi:10.1007/ s10555-007-9056-0

41. Rankin EB, Giaccia AJ (2008) The role of hypoxia-inducible factors in tumorigenesis. Cell Death Differ 15(4):678-685. doi:10.1038/cdd.2008.21

42. Boss MK, Bristow R, Dewhirst MW (2014) Linking the history of radiation biology to the hallmarks of cancer. Radiat Res 181(6):561-577. doi:10.1667/RR13675.1

43. Burroughs SK, Kaluz S, Wang D, Wang K, Van Meir EG, Wang B (2013) Hypoxia inducible factor pathway inhibitors as anticancer therapeutics. Future Med Chem 5(5):553-572. doi:10. 4155/fmc. 13.17

44. Thiery JP (2002) Epithelial-mesenchymal transitions in tumour progression. Nat Rev Cancer 2(6):442-454. doi:10.1038/nrc822

45. Thiery JP, Acloque H, Huang RY, Nieto MA (2009) Epithelialmesenchymal transitions in development and disease. Cell 139(5):871-890. doi:10.1016/j.cell.2009.11.007

46. Barcellos-Hoff MH (1993) Radiation-induced transforming growth factor beta and subsequent extracellular matrix reorganization in murine mammary gland. Cancer Res 53(17):3880-3886

47. Jung JW, Hwang SY, Hwang JS, Oh ES, Park S, Han IO (2007) Ionising radiation induces changes associated with epithelialmesenchymal transdifferentiation and increased cell motility of A549 lung epithelial cells. Eur J Cancer 43(7):1214-1224. doi:10.1016/j.ejca.2007.01.034

48. Lopez-Novoa JM, Nieto MA (2009) Inflammation and EMT: an alliance towards organ fibrosis and cancer progression. EMBO Mol Med 1(6-7):303-314. doi:10.1002/emmm.200900043

49. Yuan W, Yuan Y, Zhang T, Wu S (2015) Role of Bmi-1 in regulation of ionizing irradiation-induced epithelial-mesenchymal transition and migration of breast cancer cells. PLoS One 10(3):e0118799. doi:10.1371/journal.pone.0118799

50. Biswas S, Guix M, Rinehart C, Dugger TC, Chytil A, Moses HL et al (2007) Inhibition of TGF-beta with neutralizing antibodies prevents radiation-induced acceleration of metastatic cancer progression. J Clin Invest 117(5):1305-1313. doi:10.1172/ JCI30740

51. Garcia-Barros M, Paris F, Cordon-Cardo C, Lyden D, Rafii S, Haimovitz-Friedman A et al (2003) Tumor response to radiotherapy regulated by endothelial cell apoptosis. Science 300(5622):1155-1159. doi:10.1126/science. 1082504

52. Park HJ, Griffin RJ, Hui S, Levitt SH, Song CW (2012) Radiation-induced vascular damage in tumors: implications of vascular damage in ablative hypofractionated radiotherapy (SBRT and SRS). Radiat Res 177(3):311-327

53. Verhaegen F, Granton P, Tryggestad E (2011) Small animal radiotherapy research platforms. Phys Med Biol 56:R55-R83

54. Barcellos-Hoff MH, Park C, Wright EG (2005) Radiation and the microenvironment-tumorigenesis and therapy. Nat Rev Cancer 5(11):867-875. doi:10.1038/nrc1735

55. Yamanaka R, Tanaka R, Yoshida S (1993) Effects of irradiation on cytokine production in glioma cell lines. Neurol Med Chir 33(11):744-748

56. Satoh E, Naganuma $H$, Sasaki A, Nagasaka M, Ogata $H$, Nukui $H$ (1997) Effect of irradiation on transforming growth factor-beta secretion by malignant glioma cells. J Neurooncol 33(3):195-200

57. Raychaudhuri B, Vogelbaum MA (2011) IL-8 is a mediator of NF-kappaB induced invasion by gliomas. $J$ Neurooncol 101(2):227-235. doi:10.1007/s11060-010-0261-2

58. Ivanov VN, Hei TK (2014) Radiation-induced glioblastoma signaling cascade regulates viability, apoptosis and differentiation of neural stem cells (NSC). Apoptosis Int J Program Cell Death 19(12):1736-1754. doi:10.1007/s10495-014-1040-x

59. Wild-Bode C, Weller M, Rimner A, Dichgans J, Wick W (2001) Sublethal irradiation promotes migration and invasiveness of glioma cells: implications for radiotherapy of human glioblastoma. Cancer Res 61(6):2744-2750

60. Park CM, Park MJ, Kwak HJ, Lee HC, Kim MS, Lee SH et al (2006) Ionizing radiation enhances matrix metalloproteinase-2 secretion and invasion of glioma cells through Src/epidermal growth factor receptor-mediated p38/Akt and phosphatidylinositol 3-kinase/Akt signaling pathways. Cancer Res 66(17):8511-8519. doi:10.1158/0008-5472.CAN-05-4340

61. Badiga AV, Chetty C, Kesanakurti D, Are D, Gujrati M, Klopfenstein JD et al (2011) MMP-2 siRNA inhibits radiation- 
enhanced invasiveness in glioma cells. PLoS One 6(6):e20614. doi:10.1371/journal.pone.0020614

62. Kozin SV, Kamoun WS, Huang Y, Dawson MR, Jain RK, Duda DG (2010) Recruitment of myeloid but not endothelial precursor cells facilitates tumor regrowth after local irradiation. Cancer Res 70(14):5679-5685. doi:10.1158/0008-5472.CAN-09-4446

63. Wang SC, Yu CF, Hong JH, Tsai CS, Chiang CS (2013) Radiation therapy-induced tumor invasiveness is associated with SDF1-regulated macrophage mobilization and vasculogenesis. PLoS One 8(8):e69182. doi:10.1371/journal.pone.0069182

64. Arscott WT, Tandle AT, Zhao S, Shabason JE, Gordon IK, Schlaff CD et al (2013) Ionizing radiation and glioblastoma exosomes: implications in tumor biology and cell migration. Transl Oncol 6(6):638-648

65. Paquette B, Therriault H, Wagner JR (2013) Role of interleukin1beta in radiation-enhancement of MDA-MB-231 breast cancer cell invasion. Radiat Res 180(3):292-298. doi:10.1667/RR3240.1

66. Yu YC, Yang PM, Chuah QY, Huang YH, Peng CW, Lee YJ et al (2013) Radiation-induced senescence in securin-deficient cancer cells promotes cell invasion involving the IL-6/STAT3 and PDGF-BB/PDGFR pathways. Sci Rep 3:1675. doi:10.1038/ srep01675

67. Qian LW, Mizumoto K, Inadome N, Nagai E, Sato N, Matsumoto $\mathrm{K}$ et al (2003) Radiation stimulates HGF receptor/c-Met expression that leads to amplifying cellular response to HGF stimulation via upregulated receptor tyrosine phosphorylation and MAP kinase activity in pancreatic cancer cells. Int $\mathbf{J}$ Cancer 104(5):542-549. doi:10.1002/ijc.10997

68. Schweigerer L, Rave-Frank M, Schmidberger H, Hecht M (2005) Sublethal irradiation promotes invasiveness of neuroblastoma cells. Biochem Biophys Res Commun 330(3):982-988. doi:10. 1016/j.bbrc.2005.03.068

69. Chargari C, Clemenson C, Martins I, Perfettini JL, Deutsch E (2013) Understanding the functions of tumor stroma in resistance to ionizing radiation: emerging targets for pharmacological modulation. Drug Resist Updat 16(1-2):10-21. doi:10.1016/j. drup.2013.01.001

70. Kalluri R, Zeisberg M (2006) Fibroblasts in cancer. Nat Rev Cancer 6(5):392-401. doi:10.1038/nrc1877

71. Ohuchida K, Mizumoto K, Murakami M, Qian LW, Sato N, Nagai E et al (2004) Radiation to stromal fibroblasts increases invasiveness of pancreatic cancer cells through tumor-stromal interactions. Cancer Res 64(9):3215-3222

72. Zhou LY, Wang ZM, Gao YB, Wang LY, Zeng ZC (2012) Stimulation of hepatoma cell invasiveness and metastatic potential by proteins secreted from irradiated nonparenchymal cells. Int J Radiat Oncol Biol Phys 84(3):822-828. doi:10.1016/j.ijrobp. 2012.01.011

73. Bouchard G, Bouvette G, Therriault H, Bujold R, Saucier C, Paquette B (2013) Pre-irradiation of mouse mammary gland stimulates cancer cell migration and development of lung metastases. Br J Cancer 109(7):1829-1838. doi:10.1038/bjc. 2013.502

74. Kamochi N, Nakashima M, Aoki S, Uchihashi K, Sugihara H, Toda $\mathrm{S}$ et al (2008) Irradiated fibroblast-induced bystander effects on invasive growth of squamous cell carcinoma under cancerstromal cell interaction. Cancer Sci 99(12):2417-2427. doi:10. 1111/j.1349-7006.2008.00978.x
75. Desmarais G, Fortin D, Bujold R, Wagner R, Mathieu D, Paquette B (2012) Infiltration of glioma cells in brain parenchyma stimulated by radiation in the F98/Fischer rat model. Int J Radiat Biol 88(8):565-574. doi:10.3109/09553002.2012. 692495

76. Condeelis J, Pollard JW (2006) Macrophages: obligate partners for tumor cell migration, invasion, and metastasis. Cell 124(2):263-266. doi:10.1016/j.cell.2006.01.007

77. Russell JS, Brown JM (2013) The irradiated tumor microenvironment: role of tumor-associated macrophages in vascular recovery. Front Physiol 4:157. doi:10.3389/fphys.2013.00157

78. Sherman ML, Datta R, Hallahan DE, Weichselbaum RR, Kufe DW (1991) Regulation of tumor necrosis factor gene expression by ionizing radiation in human myeloid leukemia cells and peripheral blood monocytes. J Clin Invest. 87(5):1794-1797. doi:10.1172/JCI115199

79. O'Brien-Ladner A, Nelson ME, Kimler BF, Wesselius LJ (1993) Release of interleukin-1 by human alveolar macrophages after in vitro irradiation. Radiat Res 136(1):37-41

80. Iwamoto KS, McBride WH (1994) Production of 13-hydroxyoctadecadienoic acid and tumor necrosis factor-alpha by murine peritoneal macrophages in response to irradiation. Radiat Res 139(1):103-108

81. Nemoto K, Ishihara H, Tanaka I, Suzuki G, Tsuneoka K, Yoshida K et al (1995) Expression of IL-1 beta mRNA in mice after whole body X-irradiation. J Radiat Res 36(2):125-133

82. Thornton SC, Walsh BJ, Bennett S, Robbins JM, Foulcher E, Morgan GW et al (1996) Both in vitro and in vivo irradiation are associated with induction of macrophage-derived fibroblast growth factors. Clin Exp Immunol 103(1):67-73

83. Kim SH, Lim DJ, Chung YG, Cho TH, Lim SJ, Kim WJ et al (2002) Expression of TNF-alpha and TGF-beta 1 in the rat brain after a single high-dose irradiation. J Korean Med Sci $17(2): 242-248$

84. Timmerman R, Paulus R, Galvin J, Michalski J, Straube W, Bradley J et al (2010) Stereotactic body radiation therapy for inoperable early stage lung cancer. J Am Med Assoc 303(11):1070-1076

85. Hiniker SM, Chen DS, Knox SJ (2012) Abscopal effect in a patient with melanoma. N Engl J Med 366(21):2035. doi:10. 1056/NEJMc1203984\#SA1 (author reply-6)

86. Sosa MS, Bragado P, Aguirre-Ghiso JA (2014) Mechanisms of disseminated cancer cell dormancy: an awakening field. Nat Rev Cancer 14(9):611-622. doi:10.1038/nrc3793

87. Golden EB, Chhabra A, Chachoua A, Adams S, Donach M, Fenton-Kerimian M et al (2015) Local radiotherapy and granulocyte-macrophage colony-stimulating factor to generate abscopal responses in patients with metastatic solid tumours: a proof-of-principle trial. Lancet Oncol 16(7):795-803. doi:10. 1016/S1470-2045(15)00054-6

88. Hall EJ, Giaccia AJ (2006) Radiobiology for the radiologist, 6th edn. Lippincott Williams \& Wilkins, Philadelphia

89. Saunders M, Dische S, Barrett A, Harvey A, Gibson D, Parmar M (1997) Continuous hyperfractionated accelerated radiotherapy (CHART) versus conventional radiotherapy in non-small-cell lung cancer: a randomised multicentre trial. CHART Steering Committee. Lancet 350(9072):161-165 